\title{
Defining a Growing and Maturing Skeleton and its Relevance in Diseases that Affect Skeletal Growth, Such as X-Linked Hypophosphataemia (XLH)
}

\author{
Signe Sparre Beck-Nielsen ${ }^{1 *}$, Nella Augusta Greggio ${ }^{2}$ and Lars Hagenäs ${ }^{3}$ \\ ${ }^{1}$ Centre for Rare Diseases, Skejby, Aarhus University Hospital, Aarhus, Denmark and Department of Clinical \\ Medicine, Aarhus University, Denmark \\ ${ }^{2}$ Italian National Paediatric Coordinator Endo-ERN (SIEDP), EU-Endo-ERN Advisory Board Member, Italy \\ ${ }^{3}$ Karolinska University Hospital, Stockholm, Sweden
}

*Corresponding author: Signe Sparre Beck-Nielsen, Centre for Rare Diseases, Skejby, Aarhus University Hospital, Aarhus, Denmark and Department of Clinical Medicine, Aarhus University, Aarhus, PalleJuul-Jensens Boulevard 99, DK-8200, Aarhus, Denmark, Tel: +45-5172-9247, E-mail: sbeck-nielsen@dadlnet.dk

\begin{abstract}
The human skeleton is composed of bone, a living tissue that undergoes constant development throughout life. It is well established that changes in bone metabolism during the developmental stages of growth, modelling and remodelling determine long-lasting physiological parameters, such as final height achieved, peak bone mass, bone quality and bone health. A complex interplay of environmental, genetic, nutritional, physiological and behavioural factors plays a role in these processes. These modifiable and non-modifiable factors influence skeletal development and bone quality, as well as the occurrence of clinical conditions during adulthood, such as osteoarthritis and osteoporosis.

The phase of skeletal growth is a critical period in childhood development. Factors that adversely impact bone growth in childhood will have lifelong consequences, including short stature in adulthood and potentially also deficits in bone geometry, bone strength and bone structure.

X-linked hypophosphataemia $(\mathrm{XLH})$ is an example of a genetic condition that exerts a significant negative impact on skeletal growth and development. This rare inheritable disease is characterized by chronic renal phosphate wasting, where the lack of phosphate during the pivotal period of bone development especially in periods of rapid growth leads to rickets and poor longitudinal growth, resulting in limb deformities and disproportionate short stature.

Understanding skeletal development in disorders associated with impaired growth is important to accurately identify growth patterns that deviate from the expected norm.
\end{abstract}

The absence of a universally accepted definition for a growing skeleton poses a challenge for assessing end-ofgrowth in young adults. The authors reviewed key aspects of skeletal development, how skeletal growth is currently defined and measured, and propose definitions of a growing and maturing skeleton that would be applicable in the clinical setting, both in health and in pathological growth disorders, such as $\mathrm{XLH}$.

\section{Keywords}

Skeletal growth, Growing skeleton, Maturation, Final height, $\mathrm{X}$-linked hypophosphataemia

\section{Abbreviations}

XLH:X-Linked Hypophosphatemia; IGF-I: Insulin-like Growth Factor 1; SH: Sitting Height; PBM: Peak Bone Mass; BMC: Bone Mineral Content; aBMD: areal Bone Mineral Density; VBMD: volumetric Bone Mineral Density; DXA: Dual X-Ray Absorptiometry; HR-pQCT: High-Resolution Peripheral Quantitative Computed Tomography; CT: Computed Tomography; $1,25(\mathrm{OH})_{2} \mathrm{D}: 1,25$ Dihydroxyvitamin D; PTH: Parathyroid Hormone; PHEX: Phosphate-Regulating Endopeptidase Homolog X-Linked; FGF23: Fibroblast Growth Factor 23; MAPK: Mitogen-Activated Protein Kinase; BDAT: Bidirectional Axial Transmission; MRI: Magnetic Resonance Imaging; TW2: Tanner-Whitehouse 2nd Edition; SDS: Standard Deviation Score; ASL: Arm Span Length; ASHR: Arm Span to Height Ratio; IC: Intercondylar; IM: Intermalleolar; TBMC: Total Body BMC; TBMD: Total Body BMD

Citation: Beck-Nielsen SS, Greggio NA, Hagenäs L (2021) Defining a Growing and Maturing Skeleton and its Relevance in Diseases that Affect Skeletal Growth, Such as X-Linked Hypophosphataemia (XLH). Int J Rare Dis Disord 4:029. doi.org/10.23937/2643-4571/1710029

Accepted: April 15, 2021; Published: April 17, 2021

Copyright: (c) 2021 Beck-Nielsen SS, et al. This is an open-access article distributed under the terms of the Creative Commons Attribution License, which permits unrestricted use, distribution, and reproduction in any medium, provided the original author and source are credited. 


\section{Introduction}

The human skeleton serves multiple essential functions that include providing support for the rest of the body; providing levers for the muscles to allow movement and locomotion; protecting vital internal organs and structures; providing maintenance of mineral homeostasis and the acid-base balance; serving as a reservoir of growth factors and cytokines; and providing an environment for haematopoiesis within the marrow spaces [1]. The skeleton undergoes major size changes and adaptations to forces, during infancy and childhood. Imbalances in nutritional status, diseases of many origins or constitutional/genetic conditions, may affect skeletal growth and maturation, often leading to shorter stature and/or altered bone structure/geometry.

Measuring skeletal growth (as height) and body proportions as well as evaluating skeletal radiographs are useful for identifying and diagnosing children with short stature or growth disorders; the projected adult height of children is compared with the 'target height' or genetic height based on parental height [2].

X-linked hypophosphataemia (XLH), is a rare lifelong hereditary disorder characterized by renal phosphate wasting leading to chronic hypophosphataemia [3]. The altered phosphate metabolism produces skeletal mineralization abnormalities with growth retardation and short, disproportionate stature being major manifestations of the condition. Since bone undergoes growth, modelling and remodelling processes during childhood; remodelling and, to a lesser extent, modelling in adult life [4,5]; an adequate supply of essential elements, including calcium and inorganic phosphate, is critical to maintain a healthy skeletal structure throughout life.

In disorders of growth or bone pathology, such as $\mathrm{XLH}$, there is a need to define the end-of-skeletal growth. The current lack of a universal definition for the 'growing skeleton' poses a challenge to the optimal management of disorders with impaired skeletal growth and development since the aptness of certain treatments is dependent on whether or not longitudinal growth has ceased. Similarly, the definition of the attainment of final height is also inconsistent.

The authors of this paper held several working sessions to develop a standard definition for the growing skeleton that would be applicable in health and diseases with pathologic skeletal growth and development. Suggestions for the definition of skeletal growth and maturation were: (1) 'a growing skeleton increases in height and shows radiological non-fusion of growth zones' and (2) 'in children and adolescents, a skeleton should be considered to undergo skeletal maturation as long as it is accruing bone mass and bone density'.

This review article briefly describes the physiology and key milestones of normal skeletal development.
Skeletal deficits observed in conditions that are associated with pathologic growth, such as XLH, are also discussed. Furthermore, the concept of end-of-skeletal growth is discussed in the context of a lack of a universal definition. An updated definition for a 'growing and maturing skeleton' is proposed.

\section{Bone Formation}

There are four categories of bones that make up the human skeleton: long bones, short bones, flat bones and irregular bones. These different bone types undergo one of two distinct processes of skeletal development depending on the embryological origin, namely, intramembranous or endochondral ossification $[6,7]$.

\section{Intramembranous and endochondral ossification}

Intramembranous ossification is the process of replacing sheet-like connective tissue with bony tissue. This process produces most of the flat bones, i.e., craniofacial bones and part of the clavicles. Bone development occurs from mesenchymal condensations, differentiating directly into osteoblasts in the primary ossification centres without any prior cartilage formation [6-10].

Increases in human height are primarily accounted for by endochondral ossification, the process responsible for development of the long bones. In the embryological phase, chondrocytes initially create a cartilage model, followed by the invasion of osteoblasts and blood vessels into the skeletal element to create the primary ossification centre in the middle of the bone. This forms a denser bone matrix known as primary spongiosa [11]. The cartilage matrix continues to form as the foetus grows, lengthening the bone, with layers of rounded 'resting' chondrocytes at the ends and flat 'proliferative' chondrocytes towards the middle. Postnatally, secondary ossification starts to occur at centres at the end of the long bones. The growth plate can be found in between the primary and secondary ossification centres [11]. Any disturbance of the plate physiology may cause developmental abnormalities $[6,10,12,13]$.

\section{Longitudinal and appositional bone growth}

Longitudinal growth is driven by elongation of the bones caused by the proliferation and differentiation of chondrocytes at the epiphyseal growth plates $[6,14,15]$. The growth plate is a structure present in growing children, composed of columns of chondrocytes found in a germ layer near the epiphyseal bone. Chondrocytes grow in size until they are replaced by bone in the metaphyseal bone, following apoptosis and vessel invasion [11].

The main factor influencing longitudinal growth is the size of the hypertrophic chondrocyte prior to its replacement by bone. Up to $73 \%$ of bone lengthening has been attributed to the volume increase achieved by 
these hypertrophic chondrocytes [16].The regulation of chondrocytes and longitudinal growth is thought to involve both systemic factors (e.g., growth hormone, parathyroid hormone, vitamin $\mathrm{D}$, thyroid hormones, sex hormones, glucocorticoids) and local factors (e.g., insulin-like growth factor 1 (IGF-I), vascular endothelial growth factor, transforming growth factor beta 2, parathyroid hormone-related protein, leptin, integrins, prostaglandins and chondromodulin) $[16,17]$.

A considerable part of longitudinal growth occurs at the vertebral bodies, where the increase in sitting height (SH) accounts for more than half of the height gain during the pubertal growth spurt [18]. The mechanisms of growth in vertebral height are similar to those in long bones, with endochondral ossification taking place in the growth plates adjacent to the discs. Sustained mechanical loading can also modulate growth in height [19]. Vertebral bodies also grow via primary and secondary ossification centres in a process where the vertebrae form shapes that optimize the protection of the spinal cord, aid general mobility and provide support for the head and neck. The vertebral bodies continue changing and adapting via endochondral ossification into adulthood as greater mobility and stability is required [20].

Increases in longitudinal growth of the long bones only occur during the growth phase of bone development. Normal childhood growth is characterized by: (1) a rapid, decelerating infantile growth phase lasting until about 3 years of age; (2) a longer childhood phase with a steady decelerating growth velocity; and (3) the adolescent growth spurt that is marked by an initial period of rapidly accelerating growth velocity followed by deceleration until final adult height is reached [21].

Appositional growth occurs at the diaphysis of the long bone and the vertebral bodies, which changes the bone shape and increases its width $[19,22,23]$. During appositional growth of the long bones, width is added on the outside through the process of subperiosteal apposition. Layers are added to those that already exist, while bone is simultaneously removed on the inside of the medullary bone cavity via endosteal resorption the breaking down and reabsorption of bone material from the centre. Appositional growth (bone modelling) conserves the tubulation of long bones when the metaphyseal width is reduced into the diaphyseal dimension; failure in modelling may cause under- or over-tubulation. This continues throughout life, even after the cessation of longitudinal growth, in response to stresses from muscle activity or weight $[5,7,24,25]$.

\section{Bone modelling and remodelling}

Bone modelling primarily takes place in actively growing bone, where bones are shaped or reshaped by either bone formation or bone resorption occurring at a given bone surface $[4,7,26]$. In bone modelling, bone adapts to its function in response to stress from muscle activity or weight by the deposition of bone and removal of bone where required. This process provides increased strength to the bone structure, while minimizing density to maintain its lightness $[4,26,27]$. Bone modelling can still occur, to a much lesser extent, in the adult skeleton as bones adapt to permanent strain, pressure or fractures $[4,5]$.

Bone remodelling is a process that occurs once new bone has formed. Mineralized bone is removed by osteoclasts; the osteoblasts then replace the bone matrix, which has been resorbed. Osteoclasts and osteoblasts work sequentially in the bone forming unit during this process. Osteoclasts are activated on the bone surface and resorb the mineralized bone and the extracellular matrix. This creates a defect that is filled by the osteoblasts, resulting in new bone formation (Figure 1) $[1,4,28-30]$.

In childhood, bone remodelling is characterized by a positive bone turnover, with an overall increase in the amount of new bone formed compared with the levels of bone resorption. Once peak bone mass (PBM) is achieved, there is a net balance between bone resorption and bone formation, which then declines with age-related bone degeneration leading to a net loss of new bone. The bone remodelling process repairs microdamage, maintains biomechanical strength and ensures mineral homeostasis (phosphate and calcium) [4,31].

\section{Peak Bone Mass}

PBM is defined as the maximum amount of bone tissue accrued during an individual's life; this occurs after normal growth has ceased and indicates that the skeleton has fully matured [32-35]. Bone mass is commonly measured by bone mineral content (BMC) and areal or volumetric bone mineral density ( $a B M D$ or vBMD) using dual X-ray absorptiometry (DXA) or high-resolution peripheral quantitative computed tomography (HR-pQCT)/computed tomography (CT) [36]. Lifelong bone health is dependent on maximizing PBM during the critical periods of growth, bone mineralization and maturation [37]. The growth years during childhood and young adulthood are particularly important for building PBM. Almost half of adult bone mass is attained during adolescence, with $25 \%$ being acquired during and just after the peak height gain during the pubertal growth spurt [38]. A higher risk in later life for fragility fractures appears if optimal PBM is not reached and maintained during adulthood $[34,36,39]$.

\section{Factors influencing PBM}

In the healthy population, genetics can determine around $60-80 \%$ of PBM $[35,38,40]$. However, the predetermined genetic trajectory for the accrual of PBM can be influenced by modifiable environmental factors, 


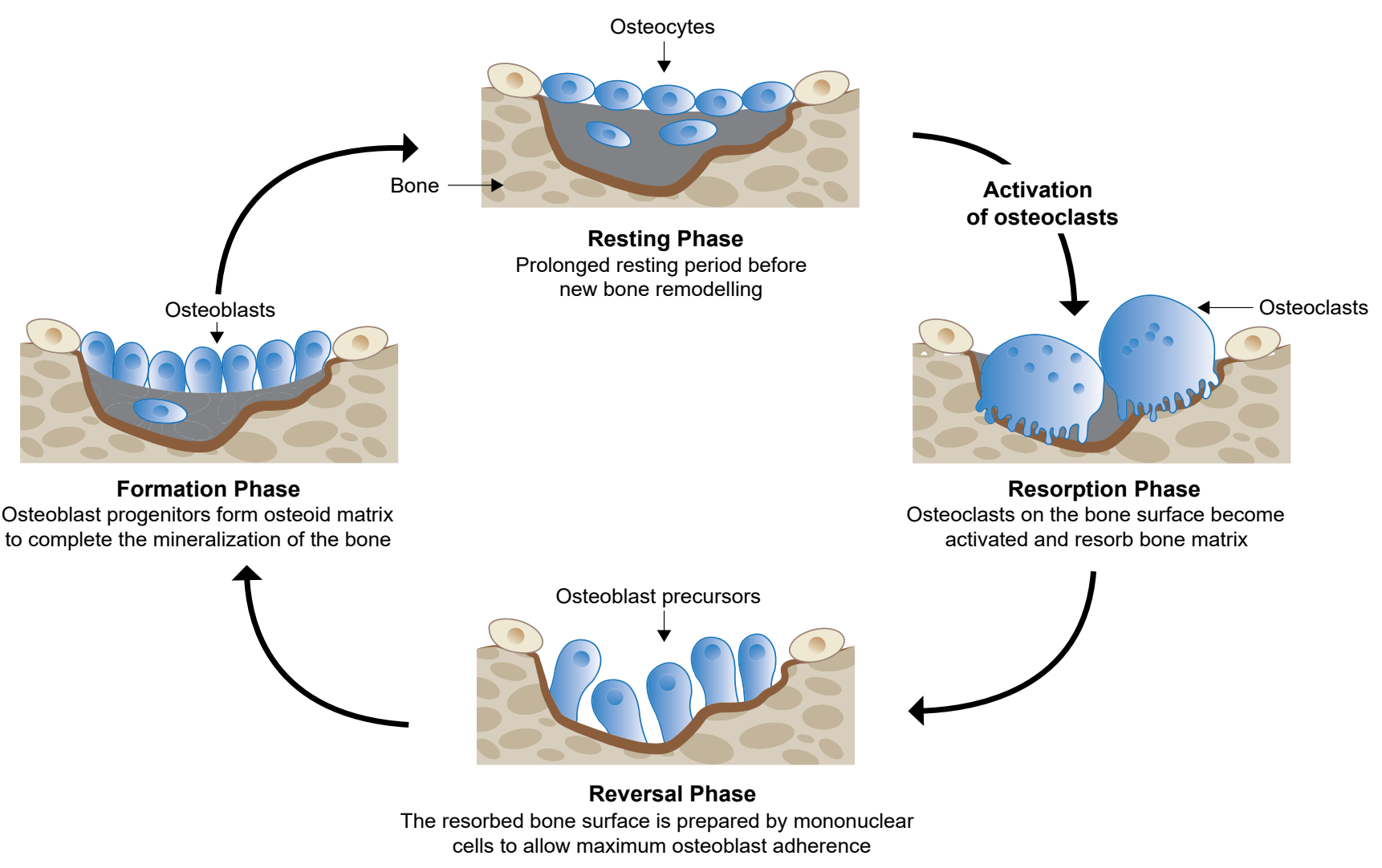

Figure 1: Bone remodelling cycle. Adapted from Moreira, et al. [30].

in particular, physical activity and optimal nutritional intake of protein, calcium and vitamin D $[33,37,38,40]$.

The impact of physical activity on bone mass acquisition during childhood is modulated by diet, particularly through the intake of protein and other essential nutrients [33]. Dietary protein enhances the production of IGF-I that stimulates the kidney production of 1,25 dihydroxyvitamin $\mathrm{D}\left(1,25(\mathrm{OH})_{2} \mathrm{D}\right)$, which, in turn, boosts intestinal absorption of calcium and inorganic phosphate, thereby positively influencing bone mineralization $[33,41]$. This production of $1,25(\mathrm{OH})_{2} \mathrm{D}$ is tightly controlled and is stimulated by parathyroid hormone (PTH). Phosphate (in the form of inorganic phosphate) plays a vital role in bone health and constitutes a major component of bone [42]. Approximately $85 \%$ of total adult body phosphate resides in the bone [43]. Adequate phosphate levels are crucial for the apoptosis of hypertrophic chondrocytes and, along with calcium, for mineralization of the newly formed bone matrix. Although dietary intake of phosphate usually exceeds the quantity of phosphate required for these processes, increased excretion of phosphate in patients with XLH results in phosphate deficiency. Maintenance of normal phosphate homeostasis is crucial for normal bone growth, especially during the phases of rapid growth [44].

Up to $50 \%$ by volume and $70 \%$ by weight of human bone is a modified form of hydroxyapatite, known as bone mineral. It is composed of calcium and phosphate $\mathrm{Ca}_{10}\left(\mathrm{PO}_{4}\right)_{6}(\mathrm{OH})_{2}$. Since adequate levels of vitamin $\mathrm{D}$ are required for the intestinal absorption of calcium and phosphate, [45] an imbalance in vitamin D levels will negatively impact the relationship between dietary calcium and phosphate intake and bone mineral density $[38,41,46]$. Decreased vitamin $D$ levels have been associated with a low bone mineral content and density, osteomalacia in adults and rickets in children [47]. The nutritional vitamin D level is one of the physiological determinants of PBM, and supplementation in infancy is associated with increased aBMD $[40,48]$. Murine models of XLH demonstrate beneficial effects of calcitriol supplementation on growth plate maturation and skeletal microarchitecture in absence of phosphate supplementation [49]. In patients with $X L H$, active vitamin $D$, in combination with phosphate supplementation, leads to improvements in rickets, limb deformity, growth and gains in height $[50,51]$.

\section{Timing of PBM attainment}

The timing of when PBM is attained has been reported to help define the lifecycle phase for optimal bone health, allowing for appropriate and timely targeting of interventions aimed at achieving optimal PBM [52]. A large age range for the attainment of PBM, $B M D$ and peak of total bone mineral content has been reported in the literature [34-36, 52-54], but in general is reported to be achieved in early adulthood.

\section{X-Linked Hypophosphataemia}

$\mathrm{XLH}$ is a rare, hereditary, progressive and lifelong renal phosphate wasting disorder caused by loss-of- 
function mutations in PHEX (phosphate-regulating endopeptidase homolog $X$-linked). For full reviews refer to Beck-Nielsen 2019 [55] and Haffner 2019 [50]. This condition is primarily inherited in an X-linked dominant pattern, whereas approximately $20-30 \%$ of cases arise from spontaneous mutations [55-57].

Although the pathogenesis of XLH is not fully understood, studies indicate that loss of PHEX function leads to the enhanced production, primarily from the osteocytes in the skeleton, of the phosphaturic hormone fibroblast growth factor 23 (FGF23). Elevated levels of serum FGF23 increase renal phosphate wasting by reducing phosphate reabsorption in the proximal renal tubule and increasing urinary phosphate excretion. FGF23 also downregulates one alpha hydroxylase, which curtails the formation of $1,25(\mathrm{OH})_{2} \mathrm{D}$ [58]. The resultant decrease in active vitamin $D$ production impairs phosphate absorption from the gut. These actions, in turn, reduce serum phosphate concentration [59].

\section{Growth retardation in XLH}

Growth retardation is a major manifestation of $\mathrm{XLH}$ in children. The abnormal, disproportionate growth is primarily seen in reduced longitudinal growth of endochondral long bones [60]. Diminished growth with declining z-scores has been reported in children with XLH as young as 6 months of age and the growth velocity continues to decline progressively during early childhood, remaining behind that of normal population growth curves [61]. In another study, growth retardation in children under 1 year of age was observed to be similar between boys and girls. However, after reaching the age of 5 years, stunting was more pronounced in boys than in girls [62].

The mechanism responsible for growth impairment in $\mathrm{XLH}$ remains to be elucidated. It has been suggested that both cartilage and bone alterations are important underlying causes for the impaired growth and long bone deformities observed in XLH [63]. Moreover, studies using murine models of $\mathrm{XLH}$ indicated that antagonizing FGF23 activity, by administering a mitogen-activated protein kinase (MAPK) pathway inhibitor, resulted not only in the acceleration of growth and improvement of rickets, but also in a normalization of growth plate structure [64]. Further studies are needed to clarify the relationship of elevated FGF23 and growth retardation in $\mathrm{XLH}$, but experimental studies suggest that blocking FGF23 action accelerates growth velocity without the risk of worsening bone deformities [17].

Treatment of XLH with oral phosphate supplements and active vitamin $D$ analogues is insufficient to normalize longitudinal growth, although improvements in biochemical parameters, in addition to partial prevention or amelioration of rickets and other manifestations of the disease have been reported $[50,62,65,66]$.

\section{Skeletal deficits in XLH}

The significant morbidity associated with XLH that impacts bones, joints and muscle, in addition to dentition and hearing, is well documented [3]. The resultant, progressive musculoskeletal abnormalities throughout life are debilitating - causing pain and stiffness, impairing mobility and physical function, decreasing range of motion and reducing health-related quality of life [67].

$\mathrm{XLH}$ is primarily characterized by chronic hypophosphataemia, which in addition to other disease factors such as changes in tissue non-specific alkaline phosphatase, pyrophosphate, calcitriol, the direct impact of FGF23 and compromised activity of the PHEX protein, exerts deleterious effects on bone development. These include reduced longitudinal growth, impaired bone mineralization, osteoid accumulation leading to osteomalacia, and an increase in skeletal osteopontin deposition contributing to the local inhibition of bone mineralization $[3,68]$. In XLH, apoptosis of the hypertrophic chondrocytes is halted, followed by a decrease in chondrocyte proliferation and loss of organization of the proliferative columns, resulting in reduced and delayed bone growth at the growth plate [69].

Hypomineralization of newly formed bone leads to accumulation of osteoid and weakened bones that may undergo deformation from applied strain and forces on the body [3]. Deformities in the lower limbs become more apparent when the child starts to ambulate [3]. Of note, mild lower limb extremity bowing has been reported in infants with XLH who may not be fully ambulatory [70]. Deformities of the weight-bearing long bones of the lower limbs include genu varum and genu valgus, with associated gait abnormalities and a typical waddling gait, and reduced muscle function [71]. Lower extremity torsion and rotation of the long bones may also be observed [72].

Upper limb deformities may be observed when the child starts crawling (Beck-Nielsen S, professional experience). Loading appears to affect the function of hypomineralized growth plates, which collectively cause leg length to be more affected than arm span in patients with XLH $[3,73]$.

\section{Bone volumetric density in XLH}

Bidirectional axial transmission (BDAT) bone ultrasound of the radius and tibia of children and young adults with XLH aged between 4.2 and 20.8 years revealed a poorer bone quality in terms of matrix stiffness and strength compared with healthy controls [74]. Trabecular thickness in the tibia was significantly higher in the patients with XLH compared with the control groups. In addition, cortical thickness in the tibia showed a tendency to be higher in patients with XLH compared with the control groups [74]. 
Moreover, a study using HR-pQCT found that adults with $\mathrm{XLH}$, in addition to having a higher total bone cross-sectional area of both the tibia and radius, had a reduced cortical thickness and a lower total VBMD [75]. Surprisingly, given that XLH is a disorder that impairs bone mineralization, patients with XLH were found to have a reduced risk of fractures compared with normal reference data [73]. Reasons for this observation and normal bone strength estimates are speculated to be caused by altered geometry with broader and shorter bones resulting in a positive impact on fracture prevention. Furthermore, the lower risktaking behaviour may also contribute to the fracture risk reduction in XLH [75].

\section{Defining Growth or End-of-Growth}

The importance of the growth phase in bone development to define optimal bone structure and mass is well established [76]. Although the distinct phases of skeletal development in healthy individuals have been studied in detail [7], similar data for patients with pathological growth conditions are scanty. Understanding skeletal development in disorders associated with impaired growth is important to accurately identify growth patterns that deviate from the expected norm. This will assist in determining whether a decrease in growth velocity is a natural cause of a disease associated with growth disturbance, i.e. $\mathrm{XLH}$, at that particular stage of skeletal development, or indicates the need for optimized medical treatment.

At present, there is no universal definition for the end-of-skeletal growth [2]. Broad parameters that have been used in the scientific literature to define growth include growth velocity associated with final height, bone age, epiphyseal plate closure and chronological age.

\section{Growth velocity associated with final height}

A growth velocity of $<2 \mathrm{~cm} /$ year has been used to estimate final height in a study of girls with Turner syndrome receiving growth hormone therapy [77]. Although a growth velocity of zero signifies epiphyseal plate closure, [78] there is no consensus on the growth velocity value to determine near-final adult height (Table 1).

Growth velocity is considered normal when it is following a percentile line on a standard growth chart. Deviations from normal in growth velocity may occur due to natural causes of early or late puberty. In such cases, the final height is expected to be within the normal range for that child but will be obtained at an earlier or later age compared with normal average age range.

The growth velocity is lower than normal in XLH. A close observation of activity of rickets both by paracrine and radiological evaluation, and the need for treatment adjustments are necessary during the growth phase, especially during phases of rapid growth [50].

\section{Bone age}

Bone age, which represents the degree of secondary ossification in the long and short bones, [92] can be used to derive biological and skeletal maturity [93]. Ossification of the hand has been considered to represent maturation of the entire skeletal system. Bone age reported at end-of-growth varies in the literature $[84,94]$. End-of-growth definitions varied from beyond 15 years for boys and beyond 13 years for girls [95-97].

The commonest modality used to assess bone age is radiography of the left hand and wrist, which contain many bones, are easy to radiograph and are often part of the non-dominant hand and, therefore, less prone to injury [98]. Other methods to determine bone age include ultrasonography, CT and magnetic resonance imaging (MRI) [92,93]. A recent technological development, known as BoneXpert, uses digital X-ray radiogrammetry to measure cortical BMD of the second to fourth metacarpal joints and has been shown to be an accurate method for determining bone age [99]. Bone-

Table 1: Definitions of final adult height based on growth/height velocity.

\begin{tabular}{|l|l|}
\hline Reference & Definition \\
\hline Lee, et al. 2018; Tanner, et al. 1975; Tanaka, et al. 2018 [79-81] & $<1 \mathrm{~cm} /$ year \\
\hline Bourguignon, et al. 1986 [82] & $<2 \mathrm{~cm} / 6$ months \\
\hline $\begin{array}{l}\text { Burns, et al. 1981; Kim YM, et al. 2014; Lindgren, et al. 2002; } \\
\text { Pfäffle 2017 [83-86] }\end{array}$ & $<2 \mathrm{~cm} /$ year \\
\hline Van den Broeck, et al. 1995 [87] & $\begin{array}{l}\text { Linear growth velocity of } 4 \mathrm{~mm} / \text { year or less, measured over at } \\
\text { least } 6 \text { months or near-final height, defined as a growth velocity } \\
\text { of 5-9 mm/year }\end{array}$ \\
\hline Tanaka, et al. 2018 [81] & $\begin{array}{l}\text { Annual height velocity }<2 \mathrm{~cm} \text { after achieving peak velocity at } \\
\text { puberty }\end{array}$ \\
\hline Roche and Davila 1972 [88] & Four successive measurements of $<0.5 \mathrm{~cm} / 6$ months \\
\hline Filipsson and Hall 1975 [89] & $<0.5 \mathrm{~cm} / 24$ months \\
\hline Largo, et al. 1978 [90] & $<2 \mathrm{~cm} / 24$ months \\
\hline Marubini, et al. 1972 [91] & $<1 \mathrm{~cm} /$ year \\
\hline
\end{tabular}


Xpert is suitable for use in the healthy population and is useful to predict bone age and final height in children with short stature $[100,101]$, although its value in XLH is compromised by the altered bone size, and is therefore considered inapplicable.

\section{Epiphyseal growth plate closure}

Longitudinal growth occurs primarily within the long bones at the epiphyseal growth plate as well as in the vertebral bodies of the spine. During childhood, the growth plate matures and the total height of the growth plate decreases, finally closing in late puberty, with complete replacement of bone. The primary determinant for epiphyseal closure is timing of puberty and this step marks the end of longitudinal growth of the long bones and vertebrae and the attainment of final height $[15,102]$. Epiphyseal plate closure does not happen simultaneously in the skeleton and a study of union at the epiphyses at the knee involving young males/females aged 18-18.9 years showed that complete epiphyseal union of the femur, tibia and fibula occurred in males/females in $12.5 \% / 10 \%, 0 \% / 10 \%$, and $25 \% / 60 \%$, respectively $[20,103,104]$.

Techniques used to identify time of epiphyseal fusion include the Tanner-Whitehouse 2 nd edition (TW2) radius-ulna-short bone, which uses 20 regions of the bone to assess bone age [105]. Each of these regions is further split into several developmental stages, one of which identifies when epiphyseal fusion is complete [106].

\section{Spinal growth and termination}

During adolescence, the growth occurring in the spine results in an increase in $\mathrm{SH}$, which is not necessarily synchronized with the leg growth [19]. This leads to an increase in $\mathrm{SH} /$ height ratio in adolescence indicating that the spinal growth velocity is exceeding the growth velocity of the legs [107]. Although the dimensions of growth in the neural canal, as well as the inter-pedicular distance is nearly complete in early childhood, spinal growth has been reported to continue after skeletal maturity and the cessation of limb growth [19].

\section{Chronological age or maturity}

Chronological age has been used in the literature inconsistently to define end-of-growth irrespective of the nomenclature used, e.g. adult height, mature height, young adults or final height. The age of 18 years is frequently accepted as the time when the estimated final height is reached [108]. However, the exact age used for determining final stature varies from 18 to 30 years of age, with variations also between gender $[95,109,110]$.

Chronological age to determine final height is seldomly used in isolation to determine skeletal maturity, but rather in combination with other parameters such as bone age and growth velocity to determine end-of- growth more accurately. The Roche-Wainer-Thissen method, as an example, predicts adult stature based on the age, weight, stature, skeletal age and average parental height of a person [111].

\section{Rationale for Defining End-of-Growth}

The growth course for children and adolescents with slow height velocity and impaired growth, as seen in $\mathrm{XLH}$, is not well characterized in the literature. Despite having a normal birth length, individuals with XLH show impaired growth especially during infancy and early childhood [60,61]. Compared with the Centers for Disease Control and Prevention growth curves, linear height in children with XLH fell behind that of the normal population as early as 6 months of age, and progressively declined during early childhood, with all median height percentiles $<8 \%$ between the ages of 2 and 12 years [61]. Results from a multicentre study also revealed that children with XLH from the age of 2 years had a stature mean value that was persistently below -2 standard deviation score (SDS) of normal reference values in healthy children [60].

Applying standard growth charts used for the general population to patients with XLH could likely lead to the underestimation of improvements in children and adolescents with XLH and pathological growth. In XLH management, inaccuracies in measuring or monitoring growth may result in treatment cessation before the full benefits of restoring phosphate homeostasis and achieving final height are realized. Growth curves that are specifically developed for patients with XLH will shed light regarding the onset of reduced growth velocity and help characterize the course of growth from birth to adulthood. A widely accepted definition of end-of-growth, aided by XLH-specific growth charts, will guide optimal management strategies and treatment guidelines.

\section{Precedence with Disease-Specific Growth Charts}

Disease-specific growth charts are important tools that help to understand the growth pattern and pathogenesis of hereditary diseases associated with growth failure [112]. A precedent for growth curves in diseases affecting growth has already been set. Diseasespecific growth charts are available for achondroplasia, sickle cell anaemia, Turner syndrome, Williams syndrome and Noonan syndrome [112-114]. Specific growth charts have also been developed for disorders that are associated with height increase in a population, which is the case for patients with Marfan syndrome who often have a tall stature [115]. In addition, growth charts for children with XLH are now available [61]. For many rare syndromes, sufficient longitudinal growth data for varying individual patterns is usually impossible to collate to establish meaningful growth charts. Therefore, current practice also utilizes normal population growth charts with extended SD-lines down to -5SDS to track children with extreme short stature. 


\section{Alternative Methods to Measure Skeletal Growth}

As longitudinal growth in the endochondral long bones is largely affected in XLH, and in addition, eventual bowing of the long bones may affect the height measurements, other methods of measuring skeletal growth in pathologic growth conditions may be considered.

\section{Arm span length}

When the measurement or interpretation of standing height represents a challenge, especially in the presence of gradually bowing of the lower extremities, arm span length (ASL) can be considered. ASL is a commonly used body parameter for predicting height, [116-118] and has proven useful to identify individuals with disproportionate growth abnormalities and skeletal dysplasia as well as to predict age-related loss in stature [117]. The arm span to height ratio (ASHR) in normal individuals is usually around one, but it differs between children and adults (age-dependent), gender and ethnic groups [118]. ASL may also be useful in monitoring the longitudinal bone growth at a site not affected by weight bearing [117].

\section{Intercondylar/intermalleolar distance}

The intercondylar (IC) and intermalleolar (IM) distance are measured at the knee or the ankle respectively, using a measuring tape with the patient in a standing position. This measurement is used to assess valgus or varus leg deformities. Performing IC and IM measures at clinical visits will reveal a worsening in a leg deformity.

\section{Sitting height}

$\mathrm{SH}$ is measured from the vertex of the head to the seated buttocks by a normal stadiometer, with the patient sitting on a stool subtracting the height of the stool from the measured height. The SH can be used instead of stature, if height cannot be accurately measured because of lower limb deformities, revealed by the IC/IM values [107]. A multicentre study involving 76 children with XLH reported that SH/height ratio SDS increased significantly during late childhood/ adolescence. The reduction in height SDS in XLH was thus primarily driven by the reduced growth of the lower limbs and is suggestive of a dissociated growth retardation primarily affecting the long weight-bearing bones. The degree of leg bowing was only weakly associated with leg length [60].

\section{Proposing a Definition for a Growing and Maturing Skeleton}

The absence of a universally accepted single definition for a growing skeleton poses a challenge for the assessment of the end-of-growth in young adults.

A definition that may be adapted to be applicable to disorders affecting bone growth and bone shape will raise awareness on disease-specific growth patterns and address the possible pitfalls when interpreting height data. It will also aid in the assessment of new therapies and the monitoring of the response to new and existing therapies. The understanding and definition of a growing and maturing skeleton may be divided into two modalities:

\section{Achieving final height}

Individuals affected by disorders that impair skeletal growth and development exhibit a growth pattern that deviates from and falls behind that of standard growth curves. The growth pattern may even be dissociated with different body segments variably affected, such as in $\mathrm{XLH}$. Thus, there is a need for growth curves specifically for XLH to identify growth patterns that deviate from the expected normal growth in XLH.

Underestimation of growth improvement in patients suffering from pathological growth, i.e. when longitudinal growth goes unrecognized due to progressive deformation of the lower extremities, could lead to treatment cessation before the full benefits of therapy are realized. The use of alternative measures such as SH or ASL should be considered when estimating growth or the cessation of growth in diseases characterized by deformations of the spine or lower extremities. In XLH, the use of ASL or SH is independent of eventual bowing of the lower extremities and the lower growth velocity of the weight-bearing long bones.

Thus, in the clinical setting a proposed definition of final height achievement:

\section{In children with a normal growth pattern:}

1. The increase in height of $<0.5 \mathrm{~cm} / 6$ months in two consecutive measurements.

2. The radiological closure of the growth zones at the wrist and knee supports the decision for obtained final height.

Adapted for XLH and other diseases affecting skeletal growth, bone shape and development:

1. The increase in height of $<0.5 \mathrm{~cm} / 6$ months in two consecutive measurements, when there is no worsening of eventual deformation of the lower extremities and no worsening of an eventual scoliosis.

2. If there is worsening of deformation of the lower extremities and/or worsening of an eventual scoliosis, utilize the increase in arm span of $<0.5 \mathrm{~cm} / 6$ months in two consecutive measurements.

3. The radiological closure of the growth zones at the wrist and knee supports the decision for obtained final height.

\section{Skeletal maturation}

\section{Continued bone modelling after final height has been achieved:}

Providing a clear measure of when bone modelling/ 
appositional growth has reached its maximum is more complicated, given that it continues into adult life albeit at a slower rate. In healthy individuals, skeletal maturation can be estimated by the maximum value of bone area revealed by DXA, where normative data for comparison is available. In diseases affecting bone area, the use of DXA interpreting bone area, where the patient serves as their own control may be a suggestion, but due to the size artefact caused by wider bones in $\mathrm{XLH}$, a comparison with normal data is not applicable $[119,120]$.

\section{Achieving PBM:}

PBM, as the maximal value of bone mass is usually expressed as the maximum value of total body $B M C$ (TBMC) or total body BMD (TBMD) for a normal individual [36]. The direct measurement of when PBM is reached is challenging in diseases affecting bone area. DXA measures of both TBMC/TBMD is again confounded by diseases affecting bone area, where the wider bones in XLH makes comparison with normal DXA data inaccurate. Estimating vBMD by HR-pQCT or CT will eradicate the confounding size artifact, providing a true bone density measure in diseases affecting bone area.

A proposed definition of a maturing skeleton is:

A skeleton is still considered to be maturing when it is accruing bone mass and bone density.

Thus, the skeleton continues maturation after longitudinal growth has ceased.

\section{Conclusion}

There are many modifiable and non-modifiable factors that can influence the growth and maturation of the human skeleton. Disturbances in physiological processes that impair normal skeletal development during childhood can lead to lifelong consequences such as retarded growth and numerous bone-related deficits. XLH is an example of a hereditary, rare metabolic bone disease that is characterized by chronic hypophosphataemia. Phosphate insufficiency during the pivotal period of bone development in early life leads to rickets and poor longitudinal growth, resulting in limb deformities and short disproportionate stature.

The lack of a universal definition of a 'growing skeleton' poses a challenge in assessing end-of-growth in young adults in general. Several working sessions were held with the authors to develop a standard definition of a growing and maturing skeleton that would be applicable to both healthy and pathological skeletal growth.

The authors propose, in the clinical setting, a definition of final height achievement in children with a normal growth pattern. An adapted definition is also proposed for XLH and other diseases that affect skeletal growth, bone shape and development. A definition for a maturing skeleton is proposed as being one that is still accruing bone mass and bone density; this implies that skeletal maturation occurs after cessation of longitudinal growth.

These definitions may be beneficial to guide assessment of end-of-growth in young adults, in both health and skeletal disease. Moreover, the proposal of a definition of final height achievement addresses the pitfalls when interpreting height data in young adults with disorders affecting bone growth and bone shape.

\section{Declarations}

Dr. Beck-Nielsen reports research grants from Kyowa Kirin, receiving payment for invited speeches for Kyowa Kirin, Novo Nordisk, and PharmaCosmos, and consultancy provided for Kyowa Kirin. Dr. Greggio reports receiving payment for invited speeches for Kyowa Kirin, and consultancy provided for Kyowa Kirin. Dr. Hagenäs reports receiving payment for invited speeches for Kyowa Kirin, and consultancy provided for Kyowa Kirin. All authors state no relation for their disclosures to the submitted work.

\section{Sources of Support}

This manuscript was based on a series of meetings organized and sponsored by Kyowa Kirin International. Medical writing support was provided by Sciterion and funded by Kyowa Kirin International.

These authors contributed equally to this work.

\section{References}

1. Clarke B (2008) Normal bone anatomy and physiology. Clin J Am Soc Nephrol. 3: S131-S139.

2. Argente $J$ (2016) Challenges in the Management of Short Stature. Horm Res Paediatr 85: 2-10.

3. Beck-Nielsen SS, Mughal Z, Haffner D, Nilsson O, Levtchenko E, et al. (2019) FGF23 and its role in X-linked hypophosphatemia-related morbidity. Orphanet J Rare Dis. 14: 58.

4. Langdahl B, Ferrari S, Dempster DW (2016) Bone modelling and remodelling: potential as therapeutic targets for the treatment of osteoporosis. Ther Adv Musculoskelet Dis 8: 225-235.

5. Burr DB, Guillot GM (2012) Almost invisible, often ignored: periosteum, the living lace of bone. Medicographia 34: 221227.

6. Long F, Ornitz DM (2013) Development of the endochondral skeleton. Cold Spring Harb Perspect Biol 5: a008334.

7. Setiawati R, Rahardjo P (2018) Bone development and growth.

8. Berendsen AD, Olsen BR (2015) Bone development. Bone 80: 14-18.

9. Jin SW, Sim KB, Kim SD (2016) Development and growth of the normal cranial vault: An embryologic review. J Korean Neurosurg Soc 59: 192-196.

10. Xie Y, Zhou S, Chen H, Du X, Chen L (2014) Recent research on the growth plate: Advances in fibroblast growth 
factor signaling in growth plate development and disorders. J Mol Endocrinol 53: T11-T34.

11. Díez AR, Joyner AL (2015) Regulation of long bone growth in vertebrates; It is time to catch up. Endocr Rev 36: 646680.

12. Kenkre JS, Bassett J (2018) The bone remodelling cycle. Ann Clin Biochem 55: 308-327.

13. Burdan F, Szumiło J, Korobowicz A, Farooquee R, Patel S, et al. (2009) Morphology and physiology of the epiphyseal growth plate. Folia Histochem Cytobiol 47: 5-16.

14. Pines M, Hurwitz S (1991) The role of the growth plate in longitudinal bone growth. Poult Sci 70: 1806-1814.

15. Shim KS (2015) Pubertal growth and epiphyseal fusion. Ann Pediatr Endocrinol Metab 20: 8-12.

16. Wilsman NJ, Farnum CE, Leiferman EM, Fry M, Barreto C (1996) Differential growth by growth plates as a function of multiple parameters of chondrocytic kinetics. J Orthop Res 14: $927-936$

17. Rodríguez FS (2020) X-linked hypophosphataemic rickets and growth. Adv Ther 37: 55-61.

18. Dimeglio A, Canavese F (2012) The growing spine: How spinal deformities influence normal spine and thoracic cage growth. Eur Spine J 21: 64-70.

19. Stokes IAF, Windisch L (2006) Vertebral height growth predominates over intervertebral disc height growth in adolescents with scoliosis. Spine (Phila Pa 1976). 31: 1600-1604.

20. Miller CA, Hwang SJ, Cotter MM, Vorperian HK (2019) Cervical vertebral body growth and emergence of sexual dimorphism: A developmental study using computed tomography. J Anat 234: 764-777.

21. Sanders JO, Qiu X, Lu X, Duren DL, Liu RW, et al. (2017) The uniform pattern of growth and skeletal maturation during the human adolescent growth spurt. Sci Rep 7: 16705.

22. Boskey AL, Coleman R (2010) Aging and bone. J Dent Res 89: 1333-1348.

23. Brodin $H$ (1955) Longitudinal bone growth, the nutrition of the epiphyseal cartilages and the local blood supply: An experimental study in the rabbit. Acta Orthop Scand Suppl 20: 1-92.

24. Jepsen KJ, Puri NA (2012) The amount of periosteal apposition required to maintain bone strength during aging depends on adult bone morphology and tissue-modulus degradation rate. J Bone Miner Res 27: 1916-1926.

25. Rauch $F$ (2005) Bone growth in length and width: The Yin and Yang of bone stability. J Musculoskeletal and Neuronal Interact 5: 194-201.

26. Maggiano CM, Maggiano IS, Tiesler VG, Chi-Keb JR, Stout SD (2016) Methods and theory in bone modelling drift: Comparing spatial analyses of primary bone distributions in the human humerus. J Anat 228: 190-202.

27. Boyce BF, Xing LP (2008) Functions of RANKL/RANK/ OPG in bone modelling and remodelling. Arch Biochem Biophys 473: 139-146.

28. Crockett J, Rogers MJ, Coxon FP, Hocking LJ, Helfrich MH (2011) Bone remodelling at a glance. J Cell Sci 124: 991998.

29. Rucci N (2008) Molecular biology of bone remodelling. Clin Cases Miner Bone Metab 5: 49-56.

30. Moreira CA, Dempster DW, Baron R, Feingold KR, Anawalt
B, et al. (2019) Anatomy and ultrastructure of bone - histogenesis, growth and remodelling. In: Endotext. South Dartmouth (MA).

31. Owen R, Reilly GC (2018) In vitro models of bone remodelling and associated disorders. Front Bioeng Biotechnol 6: 134.

32. Theintz G, Law F, Slosman D, Rizzoli R (1994) Peak bone mass. Osteoporos Int 1: 7-13.

33. Bonjour JP (2016) The dietary protein, IGF-1, skeletal health axis. Horm Mol Biol Clin Investig 28: 39-53.

34. Matkovic V, Jelic T, Wardlaw GM, Ilich JZ, Goel PK, et al. (1994) Timing of peak bone mass in Caucasian females and its implication for the prevention of osteoporosis. Inference from a cross-sectional model. J Clin Invest. 93: 799808.

35. Weaver CM, Gordon CM, Janz KF, Kalkwarf HJ, Lappe JM, et al. (2016) The National Osteoporosis Foundation's position statement on peak bone mass development and lifestyle factors: A systematic review and implementation recommendations. Osteoporos Int 27: 1281-1386.

36. Lu J, Shin Y, Yen M-S, Sun SS, et al. (2016) Peak bone mass and patterns of change in total bone mineral density and bone mineral contents from childhood into young adulthood. J Clin Densitom 19: 180-191.

37. Levine MA (2012) Assessing bone health in children and adolescents. Indian J Endocrinol Metab 16: S205-S212.

38. Weaver CM (2008) The role of nutrition on optimizing peak bone mass. Asia Pac J Clin Nutr 17: 135-137.

39. Troy KL, Mancuso ME, Butler TA, Johnson JE (2018) Exercise early and often: Effects of physical activity and exercise on women's bone health. Int J Environ Res Public Health 15: 878.

40. Bonjour JP, Chevalley T, Ferrari S, Rizzoli R (2009) The importance and relevance of peak bone mass in the prevalence of osteoporosis. Salud Publica Mex 1: S5-S17.

41. Ward K (2012) Musculoskeletal phenotype through the life course: The role of nutrition. Proc Nutr Soc 71: 27-37.

42. Hernando N, Wagner CA (2018) Mechanisms and regulation of intestinal phosphate absorption. Compr Physiol 8: 1065-1090.

43. Huang X, Jiang Y, Xia W (2013) FGF23 and phosphate wasting disorders. Bone Res 2: 120-32.

44. Penido MG, Alon US (2012) Phosphate homeostasis and its role in bone health. Pediatr Nephrol 27: 2039-2048.

45. Walker A, El Demellawy D, Davila J (2017) Rickets: Historical, epidemiological, pathophysiological, and pathological perspectives. Acad Forensic Pathol 7: 240-262.

46. Kim KM, Choi SH, Lim S, Moon JH, Kim JH, et al. (2014) Interactions between dietary calcium intake and bone mineral density or bone geometry in a low calcium intake population (KNHANES IV 2008 -2010). J Clin Endocrinol Metab 99: 2409-2417.

47. Lutz LJ, Karl JP, Rood JC, Cable SJ, Williams KW, et al. (2012) Vitamin D status, dietary intake, and bone turnover in female Soldiers during military training: A longitudinal study. J Int Soc Sports Nutr 9: 38.

48. Zamora SA, Rizzoli R, Belli DC, Slosman DO, Bonjour JP (1999) Vitamin D supplementation during infancy is associated with higher bone mineral mass in prepubertal girls. $\mathrm{J}$ Clin Endocrinol Metab 84: 4541-4544. 
49. Liu ES, Martins JS, Raimann A, Chae BT, Brooks DJ, et al. (2016) 1,25-Dihydroxyvitamin D alone improves skeletal growth, microarchitecture, and strength in a murine mode of XLH, despite enhanced FGF23 expression. J Bone Miner Res 31: 929-939.

50. Haffner D, Emma F, Eastwood DM, Duplan MB, Bacchetta $\mathrm{J}$, et al. (2019) Clinical practice recommendations for the diagnosis and management of $\mathrm{X}$-linked hypophosphataemia. Nat Rev Nephrol 15: 435-455.

51. Imel EA, Biggin A, Schindeler A, Munns CF (2019) FGF23, hypophosphatemia, and emerging treatments. JBMR Plus 3: e10190.

52. Berger C, Goltzman D, Langsetmo L, Joseph L, Jackson S, et al. (2010) Peak bone mass from longitudinal data: Implications for the prevalence, pathophysiology, and diagnosis of osteoporosis. J Bone Miner Res 25: 1948-1957.

53. Baxter-Jones AD, Faulkner RA, Forwood MR, Mirwald RL, Bailey DA, et al. (2011) Bone mineral accrual from 8 to 30 years of age: An estimation of peak bone mass. J Bone Miner Res 26: 1729-1739.

54. Recker RR, Davies KM, Hinders SM, Heaney RP, Stegman MR, et al. (1992) Bone gain in young adult women. JAMA 268: 2403-2408.

55. Beck-Nielsen S, Brixen K, Gram J, Brusgaard K (2012) Mutational analysis of PHEX, FGF23, DMP1, SLC34A3 and CLCN5 in patients with hypophosphatemic rickets. J Hum Genet 57: 453-458.

56. Dixon PH, Christie PT, Wooding C, Trump D, Grieff M, et al. (1998) Mutational analysis of PHEX gene in X-Linked hypophosphatemia. J Clin Endocrinol Metab 83: 3615-3623.

57. Rajah J, Thandrayen K, Pettifor JM (2011) Clinical practice: Diagnostic approach to the rachitic child. Eur J Pediatr 170: 1089-1096.

58. Lang F, Leibrock C, Pandyra AA, Stournaras C, Wagner CA, et al. (2018) Phosphate homeostasis, inflammation and the regulation of FGF-23. Kidney Blood Press Res 43: $1742-1748$.

59. Pettifor JM (2008) What's new in hypophosphataemic rickets? Eur J Paediatr 167: 493-499.

60. Zivičnjak M, Schnabel D, Billing $H$, Staude H, Filler G, et al. (2011) Age-related stature and linear body segments in children with $\mathrm{X}$-linked hypophosphatemic rickets. Pediatr Nephrol 26: 223-231.

61. Mao M, Carpenter TO, Whyte MP, Skrinar A, Chao-Yin C, et al. (2020) Growth curves for children with X-linked hypophosphatemia. J Clin Endocrinol Metab 105: 3243-3249.

62. Cagnoli M, Richter R, Böhm P, Knye K, Empting S, et al. (2017) Spontaneous growth and effect of early therapy with calcitriol and phosphate in X-linked hypophosphatemic rickets. Pediatr Endocrinol Rev 15: 119-122.

63. Fuente R, Gil-Peña $H$, Claramunt-Taberner D, Hernández-Frías O, Fernández-Iglesias A, et al. (2018) Marked alterations in the structure, dynamics and maturation of growth plate likely explain growth retardation and bone deformities of young Hyp mice. Bone 116: 187-195.

64. Fuente R, Gil-Peña $H$, Claramunt-Taberner D, Hernández-Frías O, Fernández-Iglesias A, et al. (2019) MAPK inhibition and growth hormone: A promising therapy in XLH. FASEB J 33: 8349-8362.

65. Friedman NE, Lobaugh B, Drezner MK (1993) Effects of calcitriol and phosphorus therapy on the growth of patients with X-linked hypophosphatemia. J Clin Endocrinol Metab 76: 839-844.
66. Mäkitie O, Doria A, Kooh SW, Cole WG, Daneman A, et al. (2003) Early treatment improves growth and biochemical and radiographic outcome in X-linked hypophosphatemic rickets. J Clin Endocrinol Metab 88: 3591-3597.

67. Skrinar A, Dvorak-Ewell M, Evins A, Macica C, Linglart A, et al. (2019) The lifelong impact of X-Linked Hypophosphatemia: Results from a Burden of Disease Survey. J Endocr Soc 3: 1321-1334.

68. Bhan A, Qiu S, Rao SD, et al. (2018) Bone histomorphometry in the evaluation of osteomalacia. Bone Rep 8: 125-134.

69. Linglart A, Biosse-Duplan M, Briot K, Chaussain C, Esterle L, et al. (2014) Therapeutic management of hypophosphatemic rickets from infancy to adulthood. Endocr Connect 3: R13-R30.

70. Vakharia JD, Matlock K, Taylor HO, Backeljauw PF, Topor LS, et al. (2018) Craniosynostosis as the presenting feature of X-linked hypophosphatemic rickets. Pediatrics 141: S515-S519.

71. Veilleux LN, Cheung MS, Glorieux FH, Rauch F (2013) The muscle-bone relationship in X-linked hypophosphatemic rickets. J Clin Endocrinol Metab 98: E990-E995.

72. Ruppe MD (2017) X-linked hypophosphatemia. GeneReviews ${ }^{\circ}$.

73. Beck-Nielsen SS, Brusgaard K, Rasmussen LM, Brixen K, Brock-Jacobsen B, et al. (2010) Phenotype presentation of hypophosphatemic rickets in adults. Calcif Tissue Int 87: 108-119.

74. Raimann A, Mehany SN, Feil P, Weber M, Pietschmann $P$, et al. (2020) Decreased compressional sound velocity is an indicator for compromised bone stiffness in X-linked hypophosphatemic rickets (XLH). Front Endocrinol 11: 355.

75. Shanbhogue VV, Hansen S, Folkestad L, Brixen K, Beck-Nielsen SS, et al. (2015) Bone geometry, volumetric density, microarchitecture, and estimated bone strength assessed by HR-pQCT in adult patients with hypophosphatemic rickets. J Bone Miner Res 30: 176-183.

76. Walsh J (2015) Normal bone physiology, remodelling and its hormonal regulation. Surgery 33: 1-6.

77. Betts $P$, Butler G, Donaldson M, Dunger D, Johnston D, et al. (1999) A decade of growth hormone treatment in girls with Turner syndrome in the UK. Arch Dis Child 80: 221225.

78. Haymond M, Kappelgaard AM, Czernichow P, Biller BMK, Takano K, et al. (2013) Early recognition of growth abnormalities permitting early intervention. Acta Paediatr 102: 787-796.

79. Lee HS, Yoon JS, Park KJ, Hwang JS (2018) Increased final adult height by gonadotropin-releasing hormone agonist in girls with idiopathic central precocious puberty. PLoS One 13: e0201906.

80. Tanner JM, Whitehouse RH, Marshall WA, Carter BS (1975) Prediction of adult height from height, bone age, and occurrence of menarche, at ages 4 to 16 with allowance for midparent height. Arch Dis Child 50: 14-26.

81. Tanaka T, Yokoya S, Hoshino Y, Hiro S, Ohki N (2018) Long-term safety and efficacy of daily recombinant human growth hormone treatment in Japanese short children born small for gestational age: Final report from an open and multi-center study. Clin Pediatr Endocrinol 27: 145-157.

82. Bourguignon JP, Vandeweghe M, Vanderschueren-Lodeweyckx M, Malvaux P, Wolter R, et al. (1986) Pubertal growth and final height in hypopituitary boys: A minor role of bone 
age at onset of puberty. J Clin Endocrinol Metab 63: 376382.

83. Burns EC, Tanner JM, Preece MA, Cameron N (1981) Final height and pubertal development in 55 children with idiopathic growth hormone deficiency, treated for between 2 and 15 years with human growth hormone. Eur J Pediatr 137: $155-164$

84. Kim YM, Kim JH, Lee BH, Yoo HW, Choi JH, et al. (2014) The effect of gonadotropin-releasing hormone agonist treatment on final adult height in girls with central precocious puberty, Chicago, USA.

85. Lindgren AC, Chatelain P, Lindberg A, Price DA, Ranke $\mathrm{MB}$, et al. (2002) Normal progression of testicular size in boys with idiopathic short stature and isolated growth hormone deficiency treated with growth hormone: Experience from the KIGS. Hormone Res 58: 83-87.

86. Pfäffle R (2017) The genetics and neuroendocrinology of short-stature international study (GENESIS): Data from 15 years of surveillance of growth hormone therapy in Germany, France and the USA. Hormone Research in Paediatrics. Conference: 10th Joint Meeting of Paediatric Endocrinology. United States. 88: 493-494.

87. Van den Broeck J, Massa GG, Attanasio A, Matranga A, Chaussain JL, et al. (1995) Final height after long-term growth hormone treatment in Turner syndrome. European Study Group. J Pediatr 127: 729-735.

88. Roche AF, Davila B (1972) Late adolescent growth in stature. Pediatrics 50: 874-880.

89. Filipsson R, Hall K (1975) Prediction of adult height of girls from height and dental maturity at ages 6-10 years. Ann Hum Biol 2: 355-363.

90. Largo RH, Gasser T, Prader A, Stuetzle W, Huber PJ, et al. (1978) Analysis of the adolescent growth spurt using smoothing spline functions. Ann Hum Biol 5: 421-434.

91. Marubini E, Resele LF, Tanner JM, Whitehouse RH (1972) The fit of Gompertz and Logistic curves to longitudinal data during adolescence on height, sitting height and biacromial diameter in boys and girls of the Harpenden Growth Study. Hum Biol 44: 511-523.

92. Satoh M (2015) Bone age: Assessment methods and clinical applications. Clin Pediatr Endocrinol 24: 143-152.

93. Mughal AM, Hassan N, Ahmed A (2014) Bone age assessment methods: A critical review. Pak J Med Sci 30: 211215.

94. Carel JC, Lahlou N, Roger M, Chaussain JL (2004) Precocious puberty and statural growth. Hum Reprod Update 10: 135-147.

95. Frindik JP, Baptista J (1999) Adult height in growth hormone deficiency: Historical perspective and examples from the national cooperative growth study. Pediatrics 104: 1000-1004.

96. Rohani F, Alai MR, Moradi S, Amirkashani D (2018) Evaluation of near final height in boys with constitutional delay in growth and puberty. Endocr Connect 7: 456-459.

97. Job JC, Joab N, Toublanc JE, Canlorbe P (1984) Final results of treatment with human growth hormone. Arch Fr Pediatr 41: 477-482.

98. Greulich WW, Pyle SI (1959) Radiograph atlas of skeletal development of the hand and wrist. (2nd edn), Stanford University Press, California.

99. Thodberg HH (2009) Clinical review: An automated method for determination of bone age. J Clin Endocrinol Metab 94: 2239-2244.

100. Anink J, Nusman CM, van Suijlekom-Smit LWA, van Rijn RR, Maas M, et al. (2014) Automated determination of bone age and bone mineral density in patients with juvenile idiopathic arthritis: A feasibility study. Arthritis Res Ther 16: 424.

101. Unrath M, Thodberg HH, Schweizer R, Ranke MB, Binder $G$, et al. (2012) Automation of bone age reading and a new prediction model improve adult height prediction in children with short stature. Horm Res Paediatr 78: 312319.

102. Emons J, Chagin AS, Sävendahl L, Karperien M, Wit JM (2011) Mechanisms of growth plate maturation and epiphyseal fusion. Horm Res Paediatr 75: 383-391.

103. De Sanctis V, Maio SD, Soliman AT, Raiola G, Elalaily R, et al. (2014) Hand X-ray in pediatric endocrinology: Skeletal age assessment and beyond. Indian $\mathrm{J}$ Endocrinol Metab 18: S63-S71.

104. O'Connor J, Bogue C, Spence LD, Last J (2008) A method to establish the relationship between chronological age and stage of union from radiographic assessment of epiphyseal fusion at the knee: An Irish population study. $J$ Anat 212: 198-209.

105. Malina RM, Coelho-E-Silva MJ, Figueiredo AJ, Philippaerts RM, Hirose N, et al. (2018) Tanner-Whitehouse skeletal ages in male youth soccer players: TW2 or TW3? Sports Med 48: 991-1008.

106. Thangam $P$, Thanushkodi $K$ (2012) Skeletal bone age assessment from epiphysis/metaphysis of phalanges using Hausdorff distance. Sci Res Essays 7: 2495-2503.

107. Fredriks AM, van Buuren $S$, van Heel WJM, Dijkman-Neerincx RHM, Verloove-Vanhorick SP, et al. (2005) Nationwide age references for sitting height, leg length, and sitting height/height ratio, and their diagnostic value for disproportionate growth disorders. Arch Dis Child 90: 807-812.

108. Kato S, Ashizawa K, Satoh K (1998) An examination of the definition 'final height' for practical use. Ann Hum Biol 25: 263-270.

109. Walker RN (1974) Standards for somatotyping children: I. The prediction of young adult height from children's growth data. Ann Hum Biol 1: 149-158.

110. Lundeen $E$ (2014) The relationship between adolescent pregnancy and adult height. FASEB J 28.

111. Khamis HJ, Guo S (1993) Improvement in the Roche-Wainer-Thissen stature prediction model: A comparative study. Am J Hum Biol 5: 669-679.

112. Isojima T, Yokoya S (2017) Development of disease-specific growth charts in Turner syndrome and Noonan syndrome. Ann Pediatr Endocrinol Metab 22: 240-246.

113. Tofts L, Das S, Collins F, Burton KLO (2017) Growth charts for Australian children with achondroplasia. Am J Med Genet A 173: 2189-2200.

114. Thomas PW, Singhal A, Hemmings-Kelly M, Serjeant GR (2000) Height and weight reference curves for homozygous sickle cell disease. Arch Dis Child 82: 204-208.

115. Kwun Y, Kim SJ, Lee J, Isojima T, Doo-Seok C, et al. (2015) Disease-specific growth charts of Marfan Syndrome patients in Korea. J Korean Med Sci 30: 911-916.

116. Chen WY, Yu-Ting L, Chen Y, Ken-Chun C, Kuo BI, et al. 
(2018) Reference equations for predicting standing height of children by using arm span or forearm length as an index. J Chin Med Assoc. 81: 649-656.

117. Mohanty SP, Babu SS, Nair NS (2001) The use of arm span as a predictor of height: A study of South Indian women. J Orthop Surg (Hong Kong) 9: 19-23.

118. Quanjer PH, Capderou A, Mazicioglu MM, Aggarwal AN, Banik SD, et al. (2014) All-age relationship between arm span and height in different ethnic groups. Eur Respir J
44: 905-912.

119. Beck-Nielsen S, Brixen K, Gram J, Mølgaard C (2013) High bone mineral apparent density in children with X-linked hypophosphatemia. Osteoporos Int 24: 22152221.

120. Binkovitz LA, Henwood MJ (2007) Pediatric DXA: Technique and interpretation. Pediatr Radiol 37: 21-31. 